\title{
Effects of substratum instability on locomotion and pedal laceration in Metridium senile (Anthozoa: Actiniaria)
}

\author{
Kenneth R. N. Anthony*, Ib Svane \\ The Royal Swedish Academy of Sciences, Kristineberg Marine Research Station, Kristineberg 2130, S-450 34 Fiskebäckskil, Sweden
}

\begin{abstract}
On the west coast of Sweden, populations of the small morph of the sea anemone Metridium senile (L.) are often found associated with beds of the mussel Mytilus edulis (L.). We tested the hypothesis that instability of the secondary substratum provided by mussels affects pedal disc laceration of $M$. senile by stimulating locomotion. The instability of a subtidal bed of $M$. edulis was quantified by recording movements of individual mussels. Rates of pedal disc laceration of $M$. senile were investigated in field and laboratory experiments using live and eviscerated mussels as substrata. Field experiments showed that $M$. senile produced significantly more lacerates on live mussels than on mimic (eviscerated) mussels. In a laboratory flume experiment, the rate of laceration on mimic mussels increased significantly with the frequency of substratum perturbation (overturning) with maximum laceration rates of groups overturned once every 12 and $48 \mathrm{~h}$. Furthermore, the rate of laceration was found to be a function of anemone body size per se. During periods between overturning of the mimics, anemones showed a significant net migration from the protected lower shell to the exposed upper shell in pace with the frequency of overturning. The presence of a vertical flow velocity gradient between and above the mimics supported the hypothesis that migration was due to a rheotactic response in $M$. senile. The significance of this behavioral pattern and stimulated clonal growth in structuring populations of $M$. senile on unstable substrata is discussed.
\end{abstract}

KEY WORDS: Disturbance $\cdot$ Substratum instability $\cdot$ Sea anemone $\cdot$ Metridium senile $\cdot$ Laceration

\section{INTRODUCTION}

Disturbances are important structuring agents in marine epibioses, causing mortality and subsequent provision of free primary substrata (e.g. Osman 1977 Sousa 1984, Connell \& Keough 1985). Provision of space on secondary substrata, on the other hand, is closely linked to the life history of the organisms and to interactions between basibionts and epibionts (Wahl 1989). Interactions between basibionts and epibionts may involve anti-fouling agents and mechanisms, but also facilitative mechanisms which may be species specific (Davis et al. 1989, Pawlik 1992).

Epibenthic bivalves often provide secondary hard substratum for epifaunal assemblages (Tsuchiya \& Nishira

\footnotetext{
- Present address: James Cook University of North Queensland, Department of Marine Biology, Townsville Queensland 4811, Australia; E-mail: kenneth.anthony1@jcu.edu.au
}

1985, 1986, Lohse 1993a, b). Although benthic bivalves are generally long-lived and relatively stationary (Okamura 1986), they provide an area of substratum less stable than, for example, bedrock. The plumose sea anemone Metridium senile (L.) is often found associated with the mussel Mytilus edulis (e.g. Kaplan 1984), and in shallow ( 2 to $8 \mathrm{~m}$ deep) channels at Strömmarna on the Swedish west coast, large subtidal beds of $M$. edulis are nearly $100 \%$ covered by populations of $M$. senile. Small body size ( $<2 \mathrm{~cm}$ pedal disc diameter, $\mathrm{PDD})$ and high rates of pedal disc laceration (the mode of asexual reproduction in $M$. senile; Bucklin 1987) are characteristic features of these populations of sea anemones (Anthony \& Svane 1994). Larger forms of $M$. senile are found abundantly in sheltered and deeper localities attached directly to the rock wall and undergo pedal laceration at lower rates (see Anthony \& Svane 1994).

Spatial aggregation and movements of mussels within patches are likely to bury part of the epifauna 
on the mussels, and can be regarded as small-scale physical disturbances (Sousa 1979, Connell \& Keough 1985, Svane \& Ompi 1993). Relative to sessile encrusting species, hemisessile epifaunal species like Metridium senile may escape burial by upward/outward movements, and thus lower the risk of mortality when host mussels are turning or aggregating.

Pedal laceration, and hence clonal growth, in Metridium senile may be stimulated by high current velocities, and differential size-frequency distributions between habitats are generally assumed to result from the effect of different current regimes, and/or genetically determined differences in rate of laceration among clones (Shick 1991. Anthony \& Svane 1994). However, pedal disc laceration may also be a consequence of pedal disc locomotion in $M$. senile, and escape-recolonization events in pace with the dynamics within mussel patches are therefore likely to be imporlant features contributing to both individual (polyp) and clonal size of $M$. senile inhabiting mussel beds.

In this study, we test the hypothesis that substratum instability affects laceration by stimulating pedal disc locomotion. We demonstrate experimentally the capacity of Metridium senile to (1) undergo pedal laceration at different rates on stable and unstable substrata, (2) escape burial caused by movements of host mussels, and (3) rapidly recolonize small cleared patches provided by overturned mussels. The significance of this pattern of asexual reproduction and migratory behavior in structuring populations of $M$. senile in mussel beds is discussed.

\section{MATERIALS AND METHODS}

Study site. Strömmarna is an area of narrow channels connecting the Gullmarsfjord with the Koljofjord on the Swedish west coast (see Anthony \& Svane 1994). The channel chosen as the experimental site (Rảbergssund) is 15 to $20 \mathrm{~m}$ wide and has nearly vertical walls to depths of 2 to $8 \mathrm{~m}$. Current velocities in the channel periodically exceed $100 \mathrm{~cm} \mathrm{~s}^{-1}$, primarily generated by winds since the tidal range in this area is small $(-30 \mathrm{~cm})$. The rock walls and the bottom of the channel are dominated by a dense bed of mussels (Mytilus edulis), colonial ascidians [Botryllus schlossen (Pallas) and Botrylloides leachii (Savigny)] and large patches of sponges (Halichondria and Haliclona sp.). The mussel bed is covered up to nearly $90 \%$ by a dense population of small Metridium senile (median pedal disc diameter $<1 \mathrm{~cm}$ ).

Movements of Mytilus edulis. In order to estimate the dynamics or instability of the secondary substratum for Metridium senile, the pattern of movements of mussels within the natural mussel bed at Råbergssund was monitored. A fixed station for photographic monitoring was established on the horizontal part of the mussel bed using a $3 \mathrm{~m}$ aluminium bar mounted between 2 concrete blocks just above the mussel bed. Three spaced quadrats measuring $50 \times 50 \mathrm{~cm}$ were selected along the aluminium bar transect. The quadrats were monitored daily for a period of $5 \mathrm{~d}$ followed by weekly monitoring for 7 wk using stereophotography (see Svane 1988). Movements of mussels between days of monitoring were analysed only in the plane parallel to the focal plane. Each slide taken by the right camera was projected onto a white cardboard with a $1 \times 1 \mathrm{~cm}$ grid so that quadrats were projected $1: 2$. The outlines of identifiable mussels and their siphons photographed on Day 1 were traced onto the board with a fine marker. Successive photographs of the same quadrat were projected onto the tracings, and mussels moved $>1 \mathrm{~cm}$ or turned $>15^{\circ}$ were scored as 'moved'.

Preparation of substrata: live and mimic mussels. Approximately 200 live Mytilus edulis, measuring $8.0 \pm 1.5 \mathrm{~cm}$ in length, and carrying a group of Metridium senile attached to each shell, were collected haphazardly in Råbergssund and placed in a holding tank. For the construction of mimics, approximately 100 mussels were subsampled and eviscerated while submerged in sea water, taking care not to damage the attached anemones. Pebbles were embedded between the corresponding shells in order to ensure negative buoyancy of the mimics, and the shells were kept together with a piece of string. On both live and mimic mussels, excess anemones and lacerates were gently removed with a spatula, leaving 10 to 25 anemones at a size of 0.5 to $2.5 \mathrm{~cm}$ PDD. This method was considered advantageous, since anemones were already established on their natural secondary substratum. Bias resulting from transplantation to an alien substratum, with the following initial phase of locomotory activity described by Wahl (1985), was thereby minimized. Live and mimic mussels with the attached anemones were kept in sea water tables until used in the experiments.

Effects of mussel movements on the rate of laceration: field experiment. Mussels (30 live and 30 mimic) with Metridium senile attached to the valves were subdivided into $2 \times 6$ groups and each group of 5 mussels (or mimics) were placed in an open cage consisting of a PVC pipe $(7 \mathrm{~cm}$ tall $\times 16 \mathrm{~cm}$ inner diameter $)$ closed in the bottom by a $1 \mathrm{~mm}$ nylon mesh. Subsequently, the 12 cages were distributed haphazardly on the mussel bed in Råbergssund, and each cage was lowered into the bed so that the mussels (or mimics) inside the cage were at the same level as the surrounding mussel bed. Although movements of live mussels or disturbances to 
mimics caused by flow forces in the cages were not recorded, substratum stability was assumed to be higher in cages with mimics relative to cages with live mussels. Prior to deployment in the field, homogeneity of size (PDD) and number of anemones between groups (live, mimics), among replicates (cages) and on individual mimics or mussels within each group was verified using a nested 2-factor ANOVA (Sokal \& Rohlf 1981). During daily surveys, large starfish Asterias rubens L., which may cause physical disturbances if preying upon the mussels, were removed from the area within approximately $2 \mathrm{~m}$ from the cages. Following $24 \mathrm{~d}$ of incubation in the field, the cages were retrieved and the number of adult anemones and lacerates on mussels and mimics were recorded. Rates of laceration were calculated as described by Anthony \& Svane (1994) and difference in rate of laceration between anemones on live and mimic mussels were tested using a $t$-test (Sokal \& Rohlf 1981).

Effects of overturning on the rate of laceration: laboratory experiment. In each of 25 mimic mussels carrying groups of Metridium senile, a $70 \mathrm{~mm}$ long nylon bolt was inserted through a $5 \mathrm{~mm}$ hole drilled symmetrically through the center of each left and right valve. The mimics were arranged in a $5 \times 5$ Latin Square design on a PVC panel measuring $35 \times 47 \mathrm{~cm}$ into which a matrix of $5 \times 5$ holes was drilled for inserting the ends of the nylon bolt. This design was chosen in order to statistically control flow heterogeneity across the matrix (see Sokal \& Rohlf 1981, Krebs 1989). The panel was subsequently placed horizontally on the bottom of a flume with a field of roughness elements (consisting of 40 granite fragments at the size of the mimics) established upstream and downstream of the matrix to obtain a turbulent flow resembling field conditions. The design of the experimental flume is in accordance with the one described by Vogel (1981). In each block, the 5 groups of anemones were given 5 different treatments (frequencies of overturning): 1 group was held permanently stationary (Group S) and 4 groups were turned $180^{\circ}$ around the long axis of the mimic after intervals of $8,4,2$ and $1 / 2$ d (Groups 1/8, $1 / 4,1 / 2$ and $2 / 1$ respectively; Fig. 1). During the experiment, half the water in the flume was renewed daily and the anemones were fed a constant amount of newly hatched brine shrimp. Flow velocity approximately $10 \mathrm{~cm}$ above the anemones was kept constantly at $15 \mathrm{~cm} \mathrm{~s}^{-1}$ measured by a thermistor probe (LaBarbera \& Vogel 1976), calibrated using the method described by Vogel (1981, p. 316). The experiment was run in darkness to exclude any effects of light on anemone behavior. After $24 \mathrm{~d}$, the number of lacerates produced during the experiment on the valves of each mimic was recorded, and the mean rate of laceration per adult anemone and per replicate (mimic) was cal-

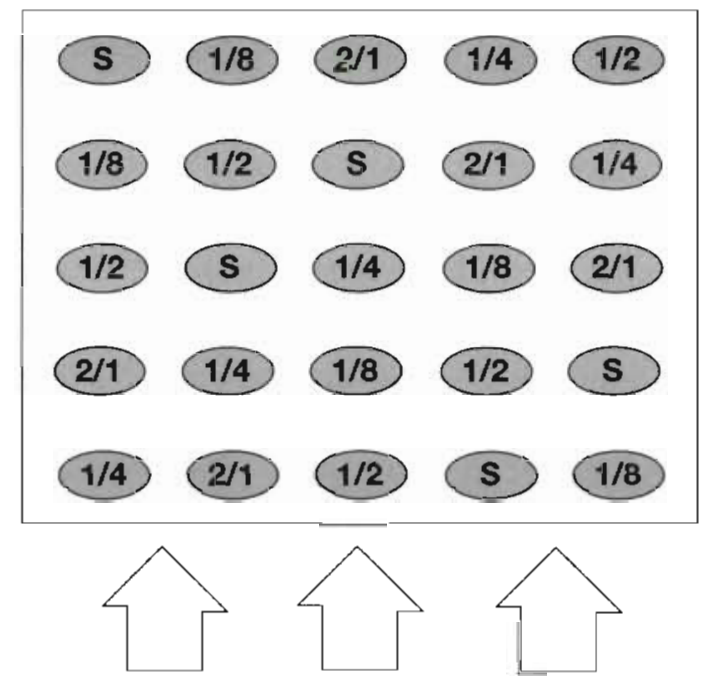

Fig. 1. Metridium senile. Experimental design (laboratory experiment) to test effects of substratum instability on locomotion and laceration. Eviscerated (mimic) mussels with groups of anemones attached to the valves were arranged in a Latin Square design and overturned at 5 different rates (S: stationary; 1/8: turned once every $8 d ; 1 / 4$ : turned once every $4 d$; 1/2: turned once every $2 d_{i} 2 / 1$ : turned twice every day) Arrows indicate direction of flow

culated. Differences in rate of laceration as an effect of treatment and position within the matrix were tested using a 3-way ANOVA (Latin Square model assuming no interaction; see Krebs 1989) followed by the Student-Newman-Keuls (SNK) multiple comparisons test (Sokal \& Rohlf 1969).

Size-specific laceration. Since different size-classes of anemones were represented within individual groups (mussels) in both field and laboratory experiments, we tested whether the rate of laceration is sizedependent in Metridium senile. From the holding tank, 36 mimics, each carrying a group of anemones, were subsampled and subdivided into 6 groups based on the size of attached anemones. Excess anemones and lacerates were removed in order to establish 6 adult PDD size-classes with intervals of $0.5 \mathrm{~cm}$ between 0.5 and $3.5 \mathrm{~cm}$ PDD. Individual mimic mussels carried 2 to 10 adult anemones each, decreasing in number with the size of anemones. The mimics were mounted on a rack consisting of a $70 \times 70 \mathrm{~cm}$ PVC frame with a stretched nylon netting to provide a matrix of $6 \times$ 6 intersections. Corresponding shells were held together at the intersections with a piece of string, and arranged in a $6 \times 6$ Latin Square design in order to control environmental heterogeneity. The rack was deployed under the pier of the harbor at Kristineberg Marine Research Station, which is characterised as a low-flow habitat. Following $24 \mathrm{~d}$ of incubation, the number of adult anemones and lacerates was re- 
corded. The relationship between size-class and rate of laceration was tested using a linear regression analysis and a Pearson's product-moment correlation (Sokal \& Rohlf 1981).

Orientated locomotion. To determine whether Metridium senile is capable of maintaining an exposed position on the mussel substratum by orientated pedal disc locomotion, migration of anemones between the downward facing (lower) and upward facing (upper) valve of the mimics was monitored during the laboratory experiment described above. Before each mimic was overturned, the numbers of adult anemones attached to the lower and upper shell were recorded. Net migration between shells during intervals between overturning was tested using a $t$-test for paired comparisons (2-tailed; Sokal \& Rohlf 1981).

To investigate whether net migration could be related to locomotion along a flow gradient (rheotactic behavior), the flow profile normal to the matrix panei was determined from the mean of 13 vertical transects $(0.8$ to $8 \mathrm{~cm})$ at different locations within the matrix. Anemone migration relative to gravity was tested by following the trajectory of 30 individual anemones attached to vertical PVC panels mounted on a flume wall (mid-water level). The circumference of the pedal disc was drawn onto the panel with a pencil, marking the initial and terminal position of each anemone. Only anemones that had moved $>1 \mathrm{~cm}$ were scored and subsequently removed. The direction of the vector, represented by the approximate centers of the 2 pedal disc outlines for each anemone, was determined relative to gravity, and the Rayleigh's test was used to test the significance of the mean direction (Zar 1984).

\section{RESULTS}

\section{Movements of mussels}

Movements of the mussels within the 3 quadrats were considerable. On average, 3 to $4 \%$ of the mussels moved $>1 \mathrm{~cm}$ or turned $>15^{\circ}$ during $24 \mathrm{~h}$. During the first $5 \mathrm{~d}, 38.2 \%$ (SE: $\pm 6.4 \%$ ) had changed positions, and after 1 mo of monitoring, $94 \%$ $( \pm 1.1 \%)$ of the mussels had moved relative to their initial positions (Fig. 2). After 2 mo, no mussels could be recognized on the photographs relative to their original positions in the quadrats. Analysis of the time series of stereophotographs revealed that a number of mussels successively appeared at the surface of the mussel bed emerging from below, while some in turn were being suppressed and buried by conspecifics

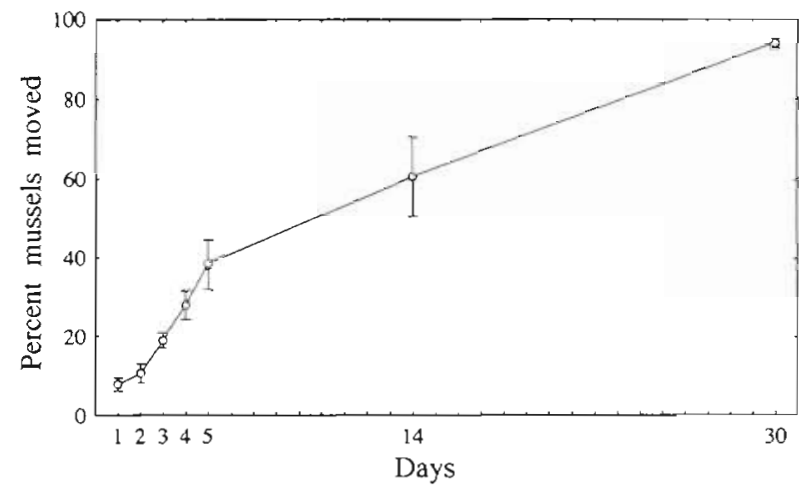

Fig. 2. Mytilus edulis. Accumulated movements in a mussel bed during a $30 \mathrm{~d}$ period. Movements are quantified as the mean percentage of mussels moved $>1 \mathrm{~cm}$ or turned $>15^{\circ}$ since the first day of monitoring ( $\pm \mathrm{SE}$ of $\mathrm{N}=3$ quadrats)

\section{Effects of substratum instability on the rate of laceration}

Field experiment

Anemones attached to live mussels in the cages showed significantly higher rates of laceration than did anemones attached to mimic mussels $(p=0.0023$, 2-tailed), indicating that laceration was stimulated by the activity of mussels in situ. Data were analysed untransformed, as arcsine-transformation did not change the conformation to ANOVA assumptions (Kolmogorov-Smirnov 1-sample test, $d=0.15, \mathrm{p}>0.20_{i}$ Sokal \& Rohlf 1981). A $t$-test with separate variance estimates was used due to heterogeneity of variances (Levene's test, $F_{1,10}=9.55, \mathrm{p}=0.011$; Statistica 1993). The mean number of lacerates produced per anemone within each tray during the experiment is depicted in Fig. 3A.

\section{Laboratory experiment}

Substratum (mimic mussel) overturning had a significant effect on the rate of laceration in Metridium

Table 1. Metridium senile. Analysis of variance on laceration data from the laboratory experiment $(5 \times 5$ Latin Square design of mimic mussels). ns: not significant; $p<0.05 ; \cdots p<0.001$

\begin{tabular}{|lrrrr|}
\hline Source of variation & df & MS & FS & p \\
\hline Frequency of overturning & 4 & 5.32 & 15.04 & $0.0001 \cdots$ \\
Position upstream/downstream & 4 & 1.72 & 4.85 & $0.0150 \cdot$ \\
Distance from flume walls & 4 & 0.79 & 2.22 & $0.2180 \mathrm{~ns}$ \\
Residual & 12 & 0.35 & & \\
\hline
\end{tabular}




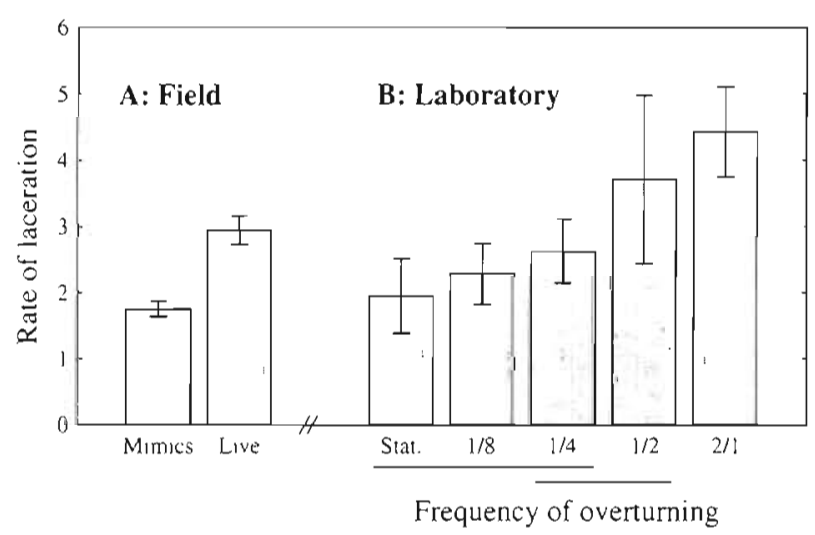

Fig. 3. Metridium senile. Rate of pedal disc laceration in anemones attached to (A) live and eviscerated (mimic) mussels in the field, and (B) mimic mussels experiencing 5 different frequencies (see Fig. 1 legend) of perturbation (overturning) in a laboratory flume. Rate of laceration calculated as the mean number of lacerates produced per adult anemone during $24 \mathrm{~d}$ $[ \pm \mathrm{SE}$ of $\mathrm{N}=5$ mimics (laboratory) or $\mathrm{N}=6$ cages (field)]. The treatment effect was significant in both experiments. Groups underlined at the same level are not significantly different by the SNK comparison

senile (Table 1, Fig. 3B). The rate of laceration after $24 \mathrm{~d}$ of the most frequently turned group was more than twice that of the stationary group (4.4 and 1.9 respectively). However, an effect of position within the matrix was also significant, since a higher rate of laceration was associated with the upstream row of mimics/ anemones. A large variation in the rate of laceration within treatment groups was evident, probably enhanced by the effect of upstream/downstream positions or distance to the flow tank walls. Data conformed to the assumptions of the ANOVA and were not transformed (Kolmogorov-Smirnov 1-sample test: $d=0.09, p>0.20$; Bartlett's test: $\chi^{2}=2.75, p=0.60$ ) .

The pattern of laceration vs disturbance in the field closely resembled the pattern found in the laboratory (Fig. 3A, B). Rates of laceration of groups experiencing an intermediate level of perturbation in the laboratory (Groups 1/8, 1/4 and 1/2) were not significantly different from the group attached to live mussels in the field $(\mathrm{p}=0.10,0.72,0.20$ respectively; all Mann-Whitney $U$-test). The most frequently overturned group in the laboratory, however, produced significantly more lacerates than the group on live mussels in the field $(p=0.006)$, which in turn lacerated more than the stationary group in the laboratory $(p=0.018)$.

\section{Size-specific laceration}

The linear relationship between pedal disc diameter and rate of laceration was highly significant $(p<0.001$,

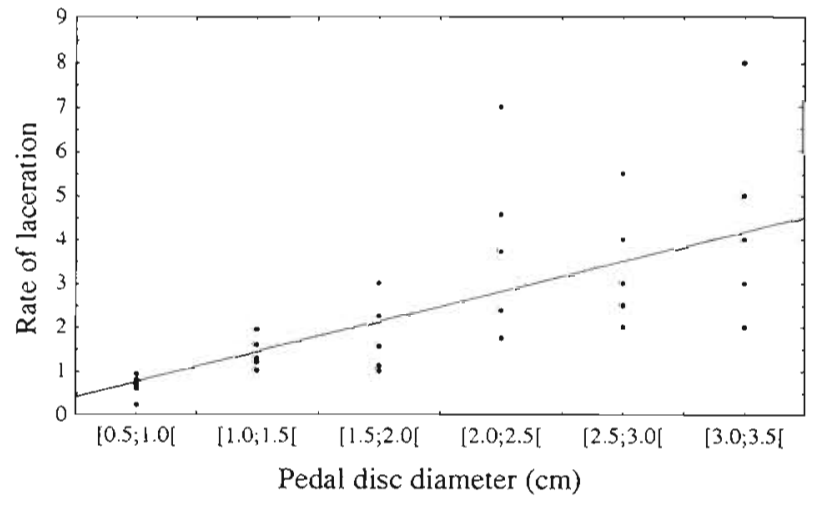

Fig. 4. Metridium senile. Size-dependent laceration. The 6 sizeclasses of anemones (each attached to $\mathrm{N}=6 \mathrm{mimic}$ mussels) were arranged on a rack in a Latin Square design and exposed in the field for $24 \mathrm{~d}$. The expected function $Y=1.53 \mathrm{PDD}-0.53$

provided a significant fit to the data $(\mathrm{p}<0.001, \mathrm{r}=0.71)$

$r=0.71$; Fig. 4). Rate of laceration of the largest sizeclass $(3.0-3.5 \mathrm{~cm})$ was more than 4 times that of the smallest size-class $(0.5-1.0 \mathrm{~cm})$. The variation in rate of laceration also increased with body size, probably enhanced by the small number of anemones per replicate mimic in the large anemone size-classes.

\section{Orientated locomotion}

During intervals between overturning, migration of anemones from the lower to the upper valves were significant for all comparisons, except for three $12 \mathrm{~h}$ (Group 2/1) intervals (t-test for paired comparisons; Fig. 5). Within the most frequently overturned groups, locomotion activity tended to increase with time. Larger anemones initially attached to lower valves curved the elongated column and projected the tentacle crown into the current. Predominantly these anemones showed rapid locomotion between lower and upper shells. Fig. 6 shows the migration of anemones from the lower toward the upper shell during $48 \mathrm{~h}$ after an overturning event. After $48 \mathrm{~h}$, all anemones initially attached to the lower valve had moved to the upper valve.

A vertical flow gradient between the flume floor (below the mimics) and the level of the uppermost tentacle crowns ( 1 to $2 \mathrm{~cm}$ above the mimics) was evident (Fig. 7). Between 4 and $8 \mathrm{~cm}$ from the flume floor, the mean flow velocity increased exponentially from $1.6 \pm 0.4$ to $12.4 \pm 1.0 \mathrm{~cm} \mathrm{~s}^{-1}$. Movements on vertical panels in the flume were randomly distributed $\left(z_{32}=\right.$ $1.59,0.20<p<0.50$ ), indicating that the net migration of anemones between shells could not be related to geotaxis. 

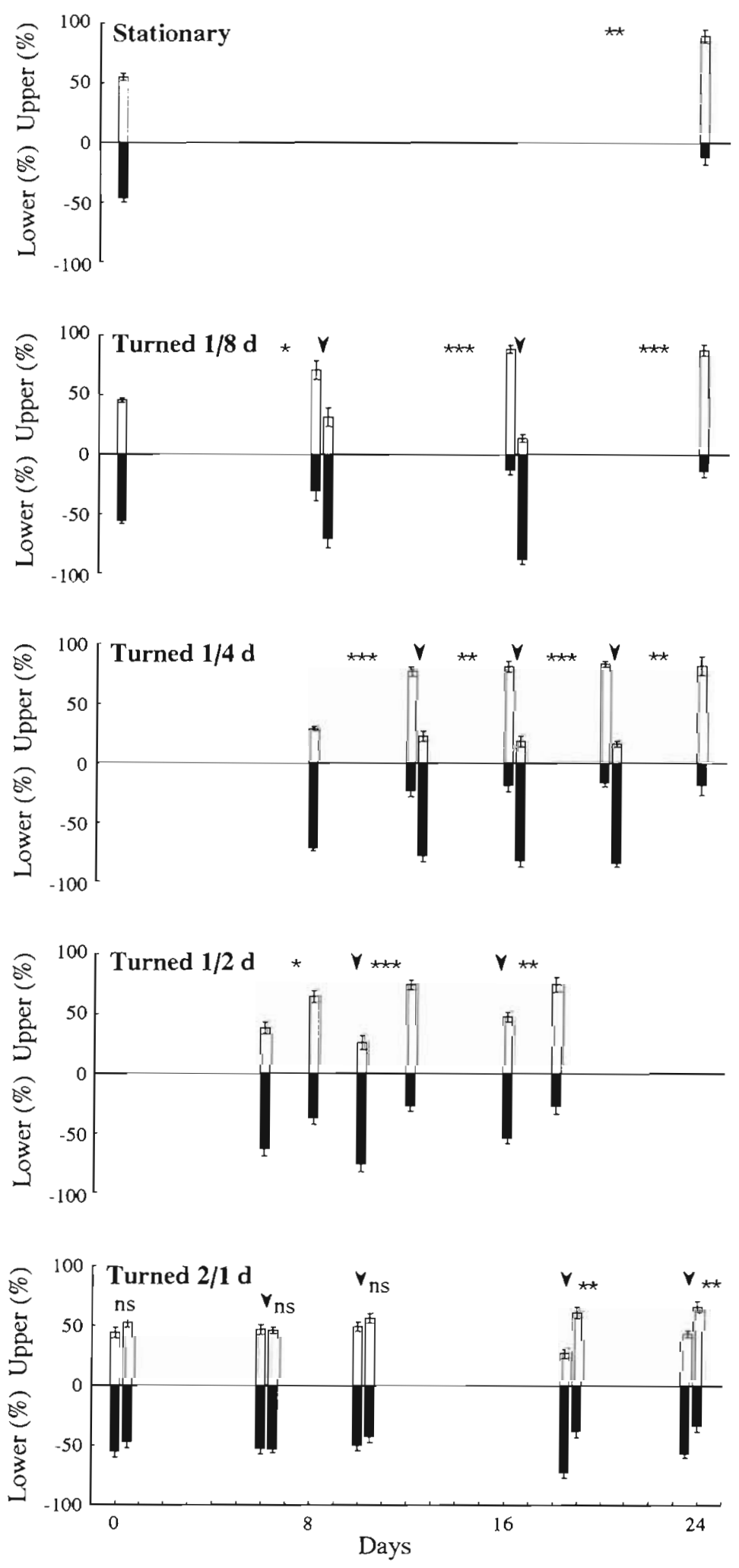

Fig. 5. Metridium senile. Migration from the lower to the upper valves of mimic mussels during intervals between overturning in a laboratory flume. Error bars are $95 \% \mathrm{CL}$. Two-sided $t$-test for paired comparisons: ns $=$ non-significant, ${ }^{\circ} p<0.05, \cdots p<0.01, \cdots p<0.001$. Arrows indicate time of overturning of the mimic mussels

\section{DISCUSSION}

The effects of substratum type on epifaunal assemblages have been studied for several intertidal species and communities (Dayton 1971, McGuiness \& Underwood 1986, Barry \& Dayton 1991, Lohse 1993a, b), but have received less attention in subtidal habitats (see Connell \& Keough 1985). Common to these studies is a general focus on the effects of substratum type and size on differential mortality, more than on epi- and basibiont interactions, differential behavior and reproductive patterns. Associations between mobile epibiont species and basibionts such as algae, sea grasses and sessile invertebrates are known for many marine organisms (Matsumasa 1994). However, an analysis of the adaptive significance is difficult, since abiotic and biotic factors interfere both spatially and temporally, closely linked to the biology of the basibionts (Sebens 1991).

The valves of the living Mytilus edulis provide substratum for many invertebrate species such as barnacles, ascidians and sea anemones. However, this type of substratum. is highly unstable, and our results showed that mussels in mussel beds are constantly moving, overturned or buried by conspecifics. Periodically, they may be confined to a less favourable environment significantly influencing the survival of the epibionts. Lohse (1993a) studied populations of 2 barnacle species and 1 limpet species, occurring on Mytilus californianus (Conrad) in the intertidal on the west coast of North America, and found that these species showed lower mortality rates and higher recruitment rates on mussels relative to on the primary substratum. This pattern was suggested to be caused by a greater substratum heterogeneity in mussel beds, but effects of mussel movements were, however, not considered.

According to Kaplan (1984), the association between Metridium senile and Mytilus edulis has a mutual advantage as the anemones confer an advantage to the host mussels by repelling predators (sea stars), and the mussels provide secondary substratum for the anemone population. Nevertheless, $M$. senile has been reported to prosper on a wide range of substratum types (Hoffmann 1976, Kaplan 1984, Sebens 1985), and this plasticity in terms of habitat choice reduces 

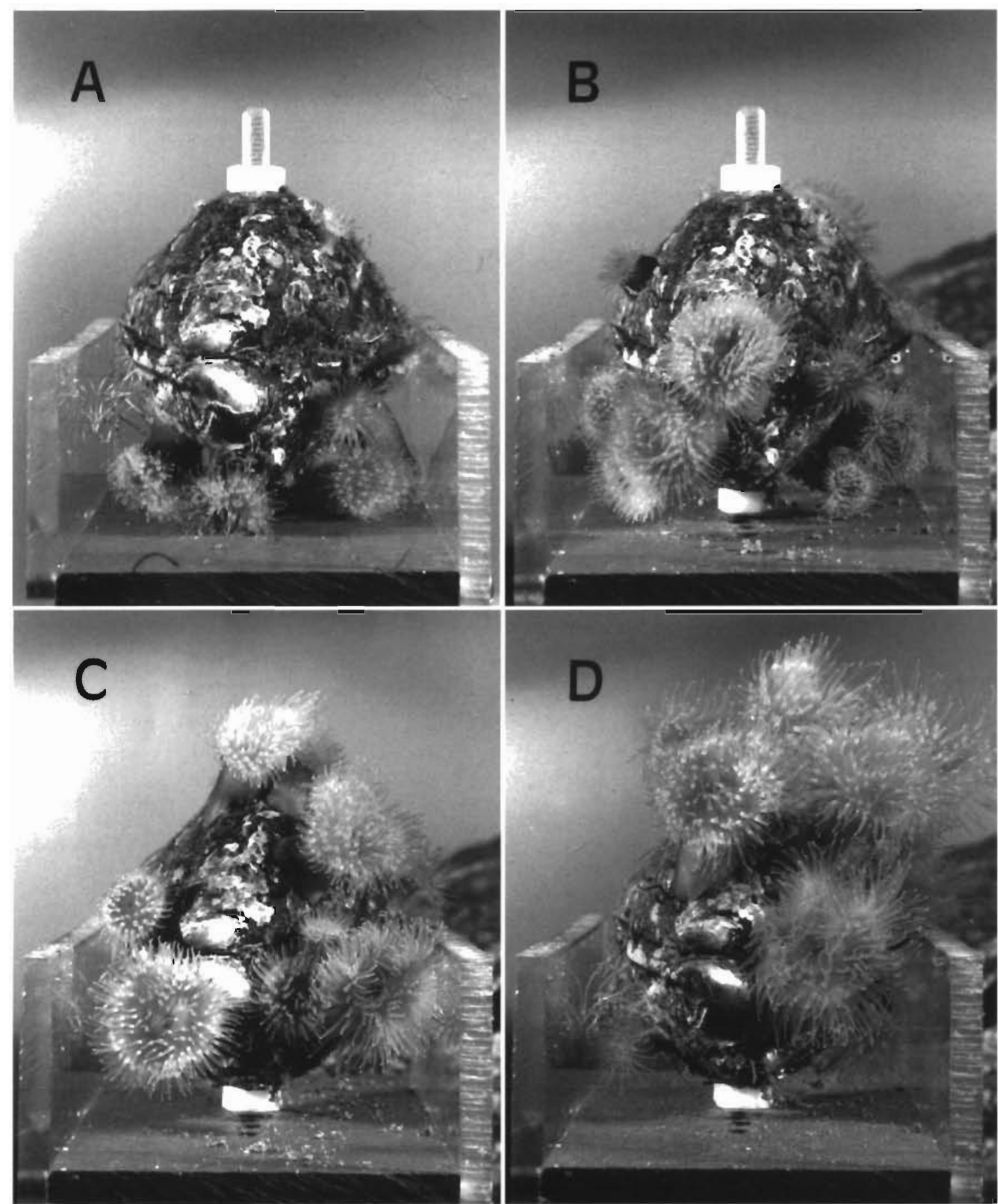

Fig. 6. Metridium senile. Orientated pedal disc locomotion in a laboratory flume. A group of 8 anemones attached to the shells of an eviscerated (mimic) Mytilus edulis at (A) $t=0 ;(B) t=12 \mathrm{~h}_{;}$(C) $t=24 \mathrm{~h}_{\text {; }}$ and (D) $t=48 \mathrm{~h}$

the likelihood of an adaptation to an epibiont relationship with $M$. edulis.

Sea anemones inhabiting mussel beds are generally smaller than conspecifics found on larger and more stable substrata (Dayton 1971, Sebens 1979). Sebens $(1981,1982)$ found that beds of Mytilus californianus function as a juvenile habitat for Anthopleura elegantissima and $A$. xanthogrammica, and that young anemones migrate to neighboring habitats where they grow to adult size. This pattern of secondary recruitment has, however, not been observed for Metridium senile. On the west coast of Sweden, large populations 


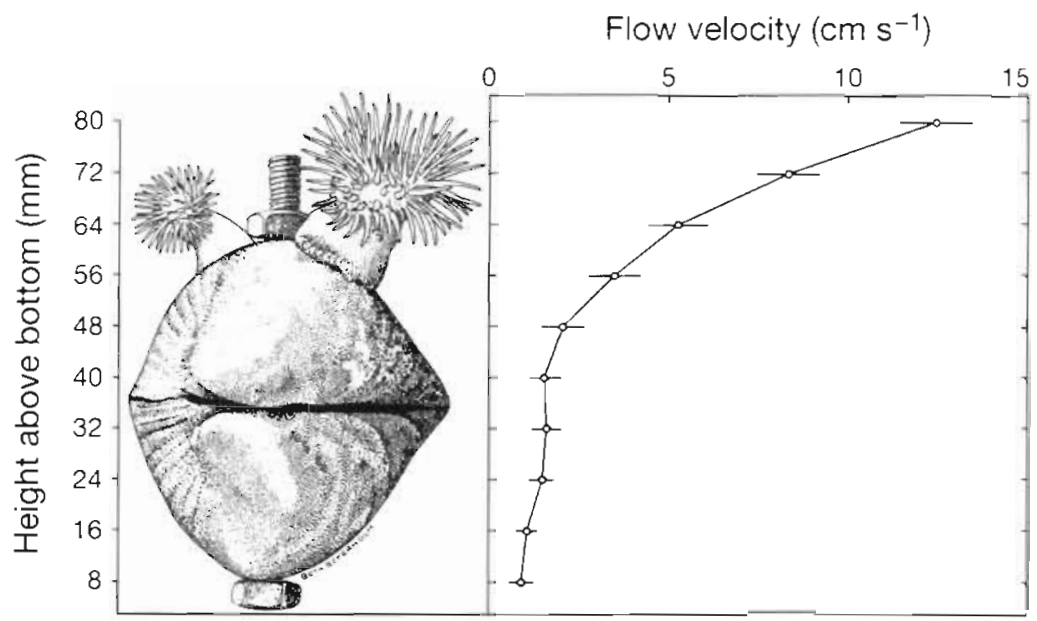

Fig. 7. Flow velocity profile along vertical transects within the matrix of mimic mussels during the flume experiment. Values are means ( $\pm 95 \% \mathrm{CL}$ ) of 13 isobath measurements determined with a calibrated thermistor probe lodgement of mussels carrying large relative to small anemones due to an increased drag (Witman \& Suchanek 1984). Large anemones may also be prevented from establishing on mussel beds if they increase the risk of mortality of the host by restricting its mobility, thereby reducing the ability of the host mussel to compete for space with other mussels (Seed 1976). Furthermore, large anemones are more likely to get squeezed and damaged between moving mussels which may be an additional factor stimulating laceration, and consequently, suppressing anemone size (K. P. Sebens pers. comm.).

Within the Strommarna population the rate of laceration increases with size per se, a factor which may contribute to maintaining a small polyp size. The

of small $M$. senile with apparently low clonal diversities, based on the low colour variation and skewed sex ratios, are generally found on shallow subtidal beds of Mytilus edulis (Anthony \& Svane 1994). Conversely, populations consisting of larger forms which occur in numerous clones (colourmorphs) are mostly found attached to the rock wall in deeper water (Anthony \& Svane 1994). This size-distribution pattern of $M$. senile is generally assumed to result from physical constraints on the anemone body plan in high-flow habitats, or genetic differences among clones (reviewed by Shick 1991. Anthony \& Svane 1994). The results of this study, however, suggest that the instability of the secondary substratum provided by mussel beds is equally important in structuring populations of $M$. senile. The stimulated pedal disc locomotion and laceration of $M$. senile on unstable substrata are likely to impose an elevated energetic cost on individual epibiont anemones, thereby reducing the amount of energy available for growth of individual ramets (polyps) and gonad tissue (see also Sebens 1979). Deposition of lacerates on the shells of the host mussel is a loss of tissue of the individual polyp, but is a potential gain in the number of clone members. The higher rate of laceration of anemones attached to unstable substrata is therefore likely to be a factor that is, in part, determining the polyp as well as the clone size of $M$. senile.

Successful utilization of the secondary substratum provided by a dynamic mussel bed involves other constraints of size on the epibiont population of Metridium senile that may render a small polyp size advantageous. For example, the maximum expected pedal disc area of the anemone is constrained by the area of the mussel valves. Another problem of anemone size is related to flow velocity and the increased risk of dis- higher rate of laceration among larger anemones in the population may be explained by their greater perimeter $(\mathrm{PDP}=\pi \mathrm{PDD})$, and the likelihood that some stochasticity is involved as to when a given part of the pedal disc will lacerate. The linear relationship between PDD (or PDP) and rate of laceration may therefore reflect a function of laceration probability, and is an important source of variation that should be considered when comparing populations of Metridium senile with different size-frequency distributions. The large variation in rate of laceration observed within individual treatment groups may therefore be magnified by the variation in anemone body size.

The consistent upward migration of anemones on the mimics in the laboratory demonstrated a capacity of active micro-habitat selection in Metridium senile Within 12 to $48 \mathrm{~h}$, a significant percentage of the anemone populations initially attached to lower mimic valves after overturning (a 'burial' situation) had moved to the upper exposed valves. As the direction of anemone movements could not be related to gravity or light, the vertical flow gradient between and above the mimics was likely to function as cue for the anemones. $M$ senile responds to increasing flow by extending the column and tentacle crown, a behavioral response that is further pronounced in the presence of food (Robbins \& Shick 1980). This rheophilic behavior results in a maximum exposure to flow, as water movement increases with distance to the mussel bed (see also Vogel 1981, Butman 1987). Due to a greater span of tentacle crown, especially large individuals may be capable of sensing the gradient in micro flow-habitat, which may explain that predominantly larger anemones (1.5 to $2.5 \mathrm{~cm}$ PDD) showed a consistent upward migration. Although the mimics in the flume were spaced in 
order to minimize contact between anemone groups or contact with the flume floor, it cannot be ruled out that the initial part of the migration process may have been stimulated by physical contact.

It is a general assumption that colonial animals possess higher potentials of recolonizing small, cleared patches than do solitary animals (Jackson 1977, 1985, Kay \& Keough 1981, Kay \& Butler 1983, Connell \& Keough 1985, Hughes \& Cancino 1985, Keough 1985). Although laceration in the solitary Metridium senile produces physiologically disjunct modules, the clonal proliferation of $M$. senile bears a functional resemblance to that of colony formation (Sebens 1979). The enhanced clonal growth on unstable substrata, in concert with the capability of orientated locomotion, may render $M$. senile comparable, or even superior, to sessile colonial animals in terms of recolonizing small patches on the secondary substratum.

The results of this study suggest that instability of the secondary substratum is an important factor influencing the behavioral pattern as well as the pattern of asexual reproduction of Metridium senile. By interfering with individual as well as clonal growth, substratum dynamics may be partly responsible for the structure of populations of $M$. senile on mussel beds.

Acknowledgements. We thank the staff and management of the Kristineberg Marine Research Station for providing laboratory facilities and technical assistance. Thanks to Ken Sebens (University of Maryland), Craig Young (Harbor Branch Oceanographic Institution, Florida), Niel Bruce (Zoological Museum, University of Copenhagen), and to Pia Rheinländer for critical reading and comments on the manuscript. This research was supported by the Nordic Academy for Advanced Studies (NorFa), the Axel Hemmingsen Grant (University of Copenhagen), and the Hierta-Retzius Foundation (Royal Swedish Academy of Sciences) to K.R.N.A., and by the Swedish Natural Science Research Council, contract no. B-BU 08526-310, to I.S.

\section{LITERATURE CITED}

Anthony KRN, Svane I (1994) Effects of flow habitat on body size and reproductive patterns in the sea anemone Metridium senile (L.) in the Gullmarsfjord, Sweden. Mar Ecol Prog Ser 113:257-269

Barry PB, Dayton PK (1991) Physical heterogeneity and the organisation of marine communities. In: Kolasa J, Pickett STA (eds) Ecological heterogeneity. Springer-Verlag, New York, p 271-320

Bucklin A (1987) Growth and asexual reproduction of the sea anemone Metridium: comparative laboratory studies of three species. J exp mar Biol Ecol 110:41-52

Butman CA (1987) Larval settlement of soft-sediment invertebrates: the spatial scales of pattern explained by active habitat selection and the emerging rôle of hydrodynamic processes. Oceanogr mar Biol A Rev 25:113-165

Connell JH, Keough MJ (1985) Disturbance and patch dynamics of subtidal marine animals on hard substrata. In:
White PS, Pickett STA (eds) The ecology of natural disturbance and patch dynamics. Academic Press, Orlando, $p$ $125-151$

Davis AR, Targett NM, McConnell OJ, Young CM (1989) Epibiosis of marine algae and benthic invertebrates: natural products chemstry and other mechanisms inhibiting settlement and overgrowth. In: Scheuer PJ (ed) Bioorganic marine chemistry, Vol 3. Springer-Verlag, Berlin, p 85-114

Dayton PK (1971) Competition and community organization: the provision and subsequent utilization of space in a rocky intertidal community. Ecol Monogr 41:351-389

Hoffmann RJ (1976) Genetics and asexual reproduction of the sea anemone Metridium senile. Biol Bull 151:478-488

Hughes RN, Cancino JM (1985) An ecological overview of cloning in metazoa. In: Jackson JBC, Buss LW, Cook RE (eds) Population biology and evolution of clonal organisms. Yale University Press, New Haven, p 153-186

Jackson JBC (1977) Habitat area, colonization, and development of epibenthic community structure. In: Keagan BF, Ceidigh PO, Boaden PJS (eds) Biology of benthic organisms. Proc 11th Eur Mar Biol Symp. Pergamon Press, Oxford, p 349-358

Jackson JBC (1985) Distribution and ecology of clonal and aclonal benthic invertebrates. In: Jackson JBC, Buss LW, Cook RE (eds) Population biology and evolution of clonal organisms. Yale University Press, New Haven, p 297-355

Kaplan SW (1984) The association between the sea anemone Metridium senile (L.) and the mussel Mytilus edulis (L.) reduces predation by the starfish Asterias forbesii (Desor). J exp mar Biol Ecol 79:155-157

Kay AM, Butler AJ (1983) 'Stability' of the fouling communities on the pilings of two piers in South Australia. Oecologia 56:70-78

Kay AM, Keough MJ (1981) Occupation of patches in the epifaunal communities on pier pilings and the bivalve Pinna bicolor at Edinburgh, South Australia. Oecologia 48 : $123-130$

Keough MJ (1985) Effects of patch size on the abundance of sessile marine invertebrates. Ecology 65(2):423-437

Krebs CJ (1989) Ecological methodology. Harper \& Row, New York

LaBarbera MJ, Vogel S (1976) An inexpensive thermistor flowmeter for aquatic biology. Limnol Oceanogr 21:750-756

Lohse DP (1993a) The effects of substratum type on the population dynamics of three common intertidal animals. J exp mar Biol Ecol 173:133-154

Lohse DP (1993b) The importance of secondary substratum in a rocky intertidal community. J exp mar Biol Ecol 166:1-17

Matsumasa M (1994) Effect of secondary substrate on associated small crustaceans in a brackish lagoon. $\mathbf{J}$ exp mar Biol Ecol 176:245-256

McGuiness KA, Underwood AJ (1986) Habitat structure and the nature of communities on intertidal boulders. $J$ exp mar Biol Ecol 104:97-123

Okamura B (1986) Group living and the effects of spatial position in aggregations of Mytilus edulis. Oecologia 69: 341-347

Osman RW (1977) The establishment and development of a marine epifaunal community. Ecol Monogr 47:37-63

Pawlik JR (1992) Chemical ecology of the settlement of benthic marine invertebrates. Oceanogr mar Biol A Rev 30:273-335

Robbins RE, Shick JM (1980) Expansion-contraction behavior in the sea anemone Metridium senile: environmental cues and energetic consequences. In: Smith DC, Tiffon Y (eds) Nutrition in the lower Metazoa. Pergamon Press, Oxford p $101-116$ 
Sebens KP (1979) The energetics of asexual reproduction and colony formation in benthic marine invertebrates. Am Zool 19:683-697

Sebens KP (1981) Recruitment in a sea anemone population: juvenile substrate becomes adult prey. Science 213: $785-787$

Sebens KP (1982) Recruitment and habitat selection in the intertidal sea anemones, Anthopleura elegantissima (Brandt) and Anthopleura xanthogrammica (Brandt). J exp mar Biol Ecol 59:103-124

Sebens KP (1985) The ecology of the rocky subtidal zone. Am Scient 73:548-557

Sebens KP (1991) Habitat structure and community dynamics in marine benthic systems. In: Bell SS, McCoy ED, Mushinsky HR (eds) Habitat structure: the physical arrangement of objects in space. Chapman \& Hall, London, p 211-234

Seed R (1976) Ecology. In: Bayne BL (ed) Marine mussels: their ecology and physiology. Cambridge University Press, Cambridge, p 13-65

Shick JM (1991) A functional biology of sea anemones. Chapman \& Hall, London

Sokal RR, Rohlf FJ (1969) Biometry. WH Freeman \& Co, San Francisco

Sokal RR, Rohlf FJ (1981) Biometry, 2nd edn. WH Freemann \& Co, San Francisco

Sousa WP (1979) Disturbance in intertidal boulder flelds: the nonequilibrium maintenance of species diversity. Ecology 60(6): $1225-1239$

This article was submitted to the editor
Sousa WP (1984) The role of disturbance in natural communities. A Rev Ecol Syst 15:353-391

Statistica (1993) Release 4.1. StatSoft, Inc, Tulsa, OK

Svane I (1988) Recruitment and development of epibioses on artificial and cleared substrata at two sites in Gullmarsfjorden on the Swedish west coast. Ophelia 29(1):25-41

Svane I, Ompi M (1993) Patch dynamics in beds of the blue mussel Mytilus edulis (L.): effects of site, patch size, and position within a patch. Ophelia 37(3):187-202

Tsuchiya M, Nishira M (1985) Islands of Mytilus as a habitat for small intertidal animals: effect of island size on community structure. Mar Ecol Prog Ser 25:71-81

Tsuchiya M. Nishira M (1986) Islands of Mytilus as a habitat for small intertidal animals: effect of Mytilus age structure on the species composition of the associated fauna and community organization. Mar Ecol Prog Ser $31: 171-178$

Vogel S (1981) Life in moving fluids: the physical biology of flow. Willard Grant Press, Boston

Wahl M (1985) Metridium senile: dispersion and small scale colonization by the combined strategy of locomotion and asexual reproduction (laceration). Mar Ecol Prog Ser 26: $271-277$

Wahl M (1989) Marine epibiosis. I. Fouling and antifouling: some basic aspects. Mar Ecol Prog Ser 58:175-189

Witman JD, Suchanek T (1984) Mussels in flow: drag and dislodgement by epizoans. Mar Ecol. Prog Ser 16:259-268

Zar JH (1984) Biostatistical analysis, 2nd edn. Prentice Hall, London

Manuscript furst received: September 12, 1994

Revised version accepted: February 14, 1995 